\title{
Impact of wild-land fires on European air quality in 2006-2008
}

\author{
M. Sofiev ${ }^{1}$, M. Lanne ${ }^{1}$, R. Vankevich ${ }^{2}$, M. Prank ${ }^{1}$, A. Karppinen ${ }^{1}$ \\ \& J. Kukkonen ${ }^{1}$ \\ ${ }^{1}$ Finnish Meteorological Institute, Helsinki, Finland \\ ${ }^{2}$ Russian State Hydrometeorological University, St. Petersburg, Russia
}

\begin{abstract}
This paper considers the influence of wild-land fires on air quality in Europe using the spring and summer seasons of 2006-2007 as prominent examples. The preliminary results for the season 2008 will also be presented. The experience of Air Quality forecasting with the SILAM modelling system, which considers anthropogenic, natural and fire-related emission sources is discussed. The fire emission is deduced from the near-real-time MODIS satellite retrievals using two sets of products of the instrument, which are assimilated daily by the emission pre-processor. We analysed several episodes and compared the impact of fires with contributions from anthropogenic sources. For example, high concentrations of nearly all pollutants were detected in Central, Eastern and Northern Europe in late spring of 2006. Simulations showed that this episode was formed by contributions of all main sources: major wild-land fires in Russia and substantial amounts of anthropogenic and natural air pollutants were accumulated for a few days over Eastern Europe. A synchronization role was played by meteorology. Specific weather conditions promoted formation of the multi-component pollution cloud, which was then transported across most of Central and Northern Europe causing widespread allergic symptoms and other illnesses associated with poor air quality. Several other episodes were more localised. Thus, August of 2006 was particularly difficult in Portugal and Spain, but also in Finland, while August 2007 was particularly difficult in Greece. The model predictions were compared with available information from ground-based monitoring sites and the satellite retrievals. The agreement was fairly good, especially for timing of the rise and fall of concentrations, while the quality of absolute levels reproduction appeared to depend on the original fire product.

Keywords: fire assimilation system, wild-land fires, dispersion modelling, air quality.
\end{abstract}




\section{Introduction}

Wild-land fires have several effects on the environment with considerable regional and global impacts on atmospheric chemistry, air quality and on the Earth's global radiative budget [e.g. 1,2].

The approaches to evaluate the amount of pollutants emitted from wild-land fires are three-fold: using burnt-area scars, hot spot counters, and fire radiative energy [3-8, etc.]. Each of the methods has it's own advantages and drawbacks, which determine their primary area of application. In particular, the burnt-area based products are widely used for long-term evaluation of the total amount of emitted species, regardless of the exact day of the fire. Such information is useful for budget-type and long-term climatologic studies. Both hot-spots and radiative power products are used for near-real-time evaluation of actual fires, as well as for long-term assessments. The hot-spot information is usually considered to be too limited for accurate emission quantification, so it is more often used in fire alarm systems. The radiative power approach, being comparatively new, is receiving increasing attention for atmospheric composition and air quality applications, including operational air quality forecasts.

Using the above approaches or their combinations, several wild-land fire emission databases have been developed: RETRO, EDGAR, GFEDv2, etc. The difference between the inventories can be very large - orders of magnitude especially if the inventories are based on different types of satellite products [9]. One of mostly uncertain parts of many algorithms is a model, which evaluates the state of the vegetation and amount of fuel to burn as the fire efficiency, i.e. the fraction of available fuel burnt during the specific episode.

Some of the uncertainty can be avoided by using direct scaling from physically observed fire features (various temperatures seen in different parts of the infra-red part of spectrum) to the gross amount of emitted substances. As shown by Sofiev et al (this volume), such systems can provide reasonable estimates of instant emission fluxes. It is also shown that this approach is sufficiently robust to be utilised (with different emission factors, of course) for both hot-spot counts and radiative energy products. The current paper applies this methodology to the fire seasons of 2006-2008 in Europe.

During the years 2006-2008, several wild-land fire episodes have been detected in Europe. These episodes include April-May 2006 with the main origin in Eastern Europe, August 2006 fires in Russia, August 2007 in Southern Europe, April-May 2008 in Russia, as well as numerous smaller-scale episodes. They were analyzed using the hot-spot and radiative-energy products of Moderate Resolution Imaging Spectroradiometer (MODIS), which has several active-fire products, which may be used when studying the impacts of wild-land fires. The MODIS fire detection procedure exploits the strong emission of midinfrared radiation from fires [10-12].

\section{Models used for assessing the fire impact}

The MODIS data have been processed with the Fire Assimilation System (FAS) jointly developed by the Finnish Meteorological Institute and the Russian State 
Hydrometeorological University. It uses the active fire products as inputs to produce global emission fluxes from wild-land fires provided with daily resolution. The emissions are utilized by the SILAM chemical transport model $[2,13,15]$, which includes the fire-induced emission into the operational forecasts of atmospheric composition.

Both versions of FAS are based on the utilization of Level 2 MODIS Collection 4 and 5 Active Fire Products for near-real-time evaluation of actual emissions from wild-land fires. Details of the processing are described by Sofiev et al (this issue), here we just outline the main features important for the analysis below.

The FAS has two lines - FAS-TA and FAS-FRP based on temperature anomaly (hot-spot counter) and fire radiative power, respectively. These two channels are treated independently, although they have partly overlapping initial data sources: their main information comes from the $3.96 \mu \mathrm{m}$ wavelength channel of MODIS. However, processing of these data for TA and FRP is substantially different. In FAS-TA the system receives the information of detected thermal anomalies with location, temperature and detection confidence. The brightness temperature is then scaled with an empirical coefficient to an emission flux of PM 2.5. FAS-FRP is a more theoretical approach that is based on using the FRP with empirical scaling to emission rates. In current FAS-FRP the scaling is done with the approach by Ichoku and Kaufman [8]. Finally, both lines end up with PM 2.5 daily emission estimates, which are then scaled to various chemical species emission following the mean coefficients of Andreae and Merlet [1].

Particulate and gaseous emission fluxes are introduced into the air quality and emergency modelling system SILAM together with anthropogenic inventories from the European Monitoring and Evaluation Programme EMEP (http://www.emep.int).

SILAM is an air quality and emergency system that has been created to provide an environment capable of supporting various types of dispersion models and is suitable for approaching a wide range of tasks [13, 15]. The dispersion tools allow the choice of the Eulerian and Lagrangian dynamic kernels and eight different chemico-physical cocktails of species. For the current simulations, we used Eulerian dynamics and a combination of basic acid and ozone chemistry with inert particles for fire and anthropogenic primary PM emissions, as well as the sea salt production terms to account for the marine aerosol contribution. The simulations have been made over the whole of Europe with spatial resolution of about $30 \mathrm{~km}$ and hourly averaging of the output fields.

Evaluation of the output concentration fields has been done against several independent datasets.

The in-situ observations used for the model-measurement comparison were obtained from the Finnish national monitoring network (http://www. ilmanlaatu.fi), which provides in near-real-time the information about all major atmospheric constituents. Other national datasets were obtained from France, Estonia, Portugal and Germany. We also used the data from the AIRBASE 
database of European Environment Agency - for the periods and regions where the information was available.

The in-situ datasets, being historically the primary source of information about the atmospheric composition, have several significant drawbacks, which are particularly important for the evaluation of the fire-related systems. Firstly, the stations almost always provide only the surface concentrations while the hot plumes from fires can rise through the atmospheric boundary layer to free troposphere becoming essentially invisible for surface-based monitors. Secondly, quality of the in-situ data suffers from the limited representativeness of observations at a single point for the surrounding area. Since fire plumes can be quite narrow (depending on the atmospheric conditions), a small deviation of wind direction can jeopardise the whole comparison, especially if the network is not dense enough.

As a complementary set of information, we also involved the remote sensing information about the tropospheric composition obtained from several independent sources. The most straightforward source was MODIS, which provides the vertically integrated aerosol optical depth (AOD). Since the amount of aerosols in stratosphere is negligible in comparison with lower layers of troposphere, we considered this product as directly comparable with the SILAM computations with one exception: our simulations did not contain the source of crustal dust, thus missing substantial amounts of aerosols in southern Europe during the dust storms in Sahara.

For gaseous species, we utilised the OMI satellite retrievals for $\mathrm{NO}_{2}$. Here the difficulties are more substantial because the total-column-integrated $\mathrm{NO}_{2}$ concentrations fields are significantly larger than those of tropospheric-columnintegrated ones. Therefore, the overall quality and completeness of the information is lower.

\section{Results and discussion}

One of the main outcomes of the study is the time series of the European emission from fires shown in Figure 1 for the period from March 2006 until May

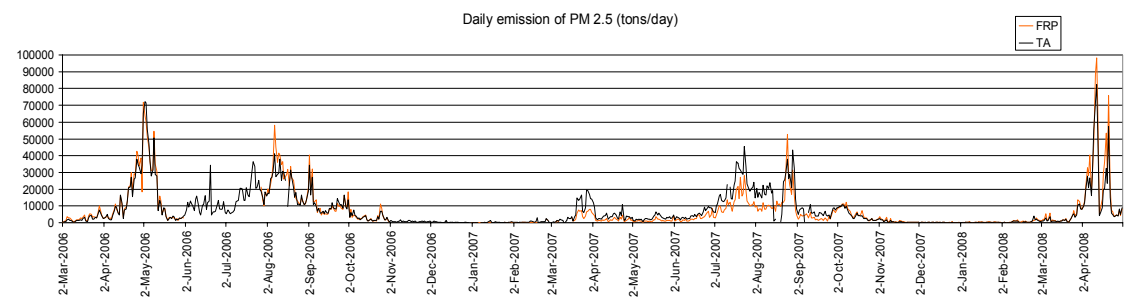

Figure 1: $\quad$ Time series of spatially integrated emission of PM 2.5 from fires in Europe based on TA (Rapid Response System) and FRP (MODIS collection 5) data. 
2008. For both completed years the system shows two clear peaks of the fire activity: late spring around May and late-summer around August. In-between in both years the intensity drops down to quite low levels due to precipitation events usually taking place in June. So far, the season of 2008 followed the template but started somewhat earlier: intensive fire-related emission took place already in the beginning of April due to strong grass burning in southern Russia and Ukraine (Figure 2).

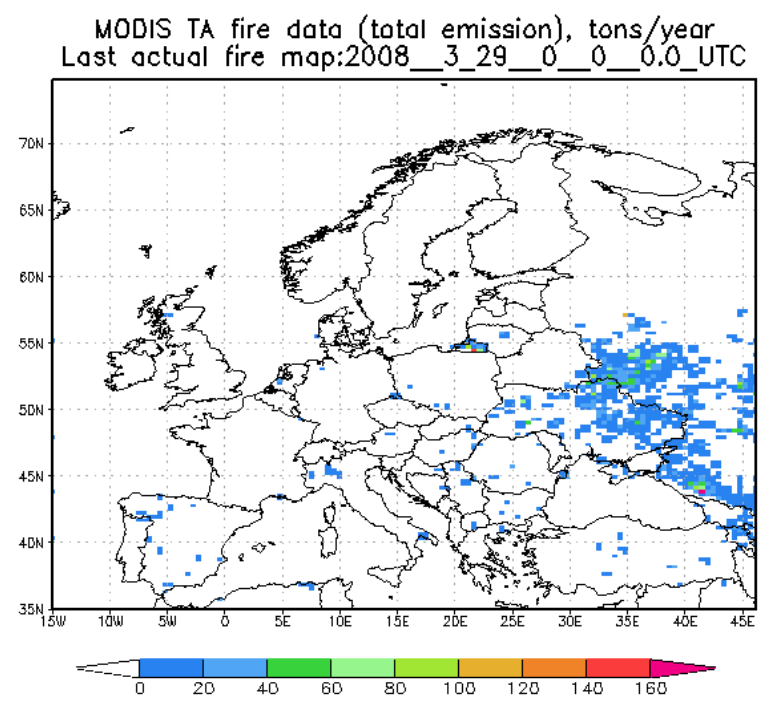

Figure 2: A map of fire-related emissions for the last week of March 2008 (TA-based).

A comparison of the fire-induced emissions with, for example, anthropogenic primary PM release to the atmosphere shows that at annual level they are practically the same: mean over 3 years of values in Figure 1 leads to $\sim 7.5$ kton of PM 2.5 day $^{-1}$. Data submitted by European countries within the scope of EMEP programme lead to $\sim 9$ kton of PM 2.5 day $^{-1}$, so that the difference between these estimates is well within the uncertainty of both values. However, the fire emission is extremely inhomogeneous in time. It is practically zero during winter and reaches up to $70 \mathrm{kton}$ of PM 2.5 day $^{-1}$ during the episodes when it seems to be entirely dominating over all other aerosol sources over the continent. For other species, the totals for NOx and SOx do not look that strong: during the episodes the fire emission is very large but still is of the same order of magnitude as the anthropogenic fluxes. However, the uncertainties of such scaling from PM 2.5 to other species using mean ratios are very high and do not allow firm quantitative conclusions.

Episode-wise, one of the strongest cases during the considered period was April-May 2006 (the first peak of fire-induced emission in Figure 1). This episode has been analysed by Saarikoski et al [2] and Sofiev et al [14] with 
regard to aerosols. In these papers, it is shown that within the plume the fireinduced particle concentrations were at least 5 times higher than those from the other sources - combined. For $\mathrm{NO}_{2}$, the situation is not so dramatic but still the SILAM simulations showed that the highest $\mathrm{NO}_{2}$ levels due to anthropogenic sources (around the Netherlands) are well comparable with the fire plume over the Central Russia (Figure 3).

Unfortunately, the OMI instrument has severe problems in observing $\mathrm{NO}_{2}$ through the dense fire smoke but a few still-available parts of the pattern outside the main plume and the most-polluted areas - over the Black Sea, Finland, the Netherlands, UK, Spain, Portugal, and North Sea showed values similar to what has been computed by SILAM. There is, however, a systematic over-estimation of the modelled values in comparison with the OMI retrievals. Its origin is not very clear because it requires independent and reliable information on tropospheric $\mathrm{NO}_{2}$ profiles.

The maps of Figure 3 confirm the analysis made in previous works for aerosols: the chemical composition of the atmosphere with regard to gaseous species, such as NOx, SOx and even NHx is strongly altered by the fire-induced emissions, which dominate inside the main smoke plume and are comparable with the anthropogenic pollution in the most contaminated parts of Europe.
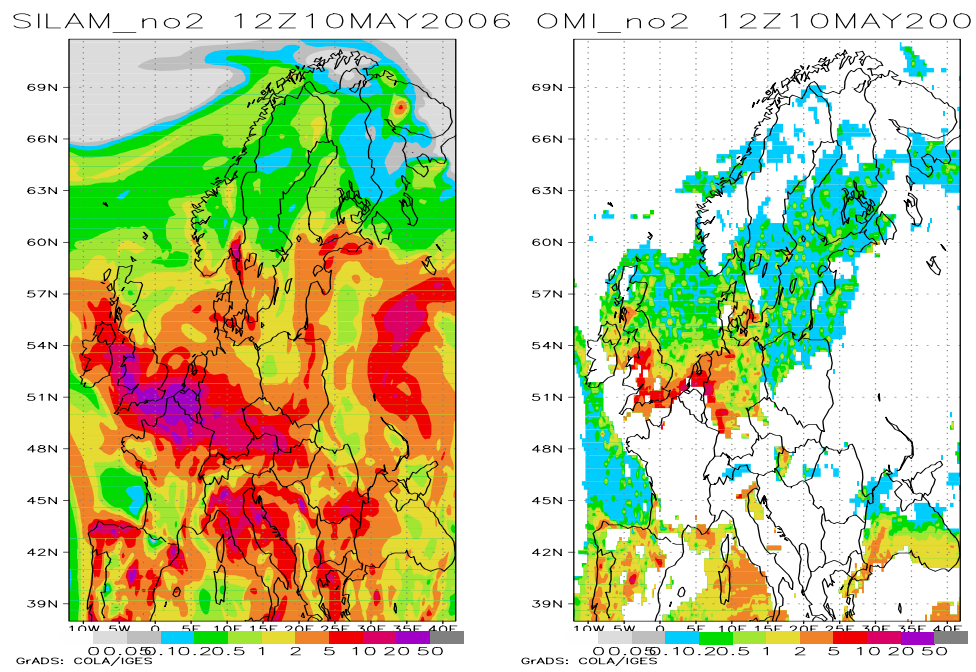

Figure 3: Maps of $\mathrm{NO}_{2}$ vertically-integrated column from SILAM simulations (left) and observed by OMI instrument onboard of Aura satellite (right). Fire-induced emissions are from FAS-TA processing, anthropogenic fluxes are provided by EMEP. OMI retrievals are generated by GIOVANNI Web-based toolset: http://daac.gsfc.nasa.gov/techlab/giovanni/. 
The episode of spring 2006 had very widespread impact because the smoke plume was transported over most of Europe during April 27 - May 10 period causing strong degradation of air quality. It should, however, be stressed that similar biomass burning episodes take place nearly every year but go more or less unnoticed because the prevailing wind direction keeps Europe upwind from the burning areas in the East. As an example,

Figure 4 shows the recent event of intensive burning in the south of Russia (remaining fires of those shown in Figure 2), which was not noticed by the European observational network due to western wind direction.
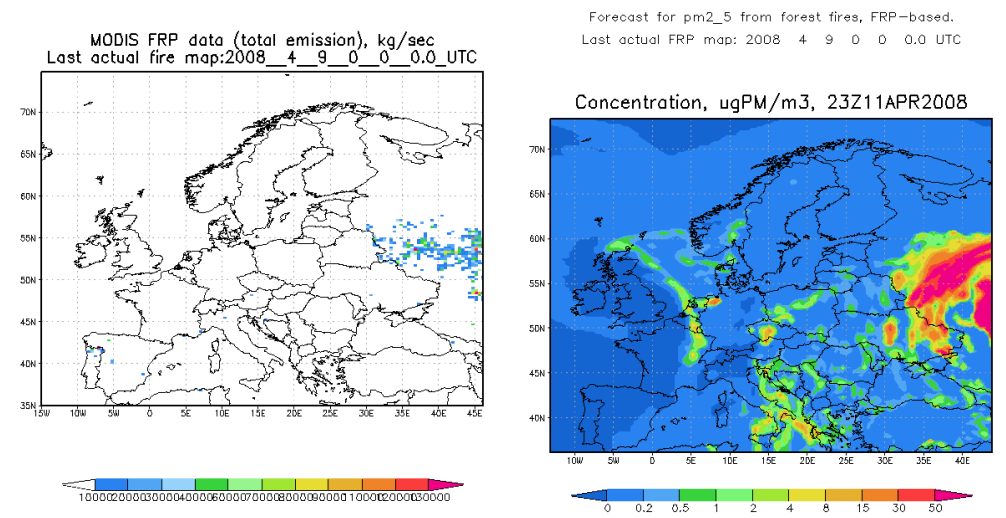

Figure 4: Distribution of biomass burning areas (left) during the first week of April 2008 and the smoke from these fires (right). Picked from the SILAM model forecast archive; unit $=\left[\mu \mathrm{g}\right.$ PM $\left.2.5 \mathrm{~m}^{-3}\right]$.

\section{Conclusions}

The biomass-burning sources of atmospheric pollution are important contributors to the atmospheric composition over Europe. Development and operational implementation of the dual-line Fire Assimilation System in the Finnish Meteorological Institute helped to improve the air quality forecasts, especially for spring and summer seasons. In the operational setup, the fire emissions are derived from hot-spot counts and fire radiative power products of MODIS instrument onboard of NASA Aqua and Terra satellites and provided, together with anthropogenic and biogenic emission fluxes to the SILAM dispersion modelling system.

The temporal distribution of fire emission intensity is extremely inhomogeneous with near-zero values during winter season and very high levels during spring and summer periods. During these "hot" seasons the impact of fires to concentrations of some species, first of all, atmospheric aerosols, can be totally dominant exceeding all anthropogenic sources combined. In average, the 
annual emissions of primary fine particles from anthropogenic and biomassburning sources are nearly the same: 9 and $7.5 \mathrm{kton}^{\mathrm{PM}} 2.5 \mathrm{day}^{-1}$, respectively.

Considered periods, albeit limited, still revealed systematic pattern with two peaks of fire intensity - in late spring and in late summer. Some of these episodes can be unnoticed by the air quality monitoring network because at least spring-time burning areas are located downwind of the European observational sites, so that the only tool for getting the information about such events are satellite retrievals.

\section{Acknowledgements}

The Fire Assimilation System of FMI has been developed within the scope of the EU-GEMS project and is currently being updated within the IS4FIRES project of the Academy of Finland. The operational forecasts have been supported by the EU-GEMS and ESA-PROMOTE projects. Networking support of the COSTES0602 Action is also appreciated.

\section{References}

[1] Andreae, M.O. \& Merlet, P., Emission of trace gases and aerosols from biomass burning. Global Biochemical Cycles, 15(4), pp. 955-966, 2001.

[2] Saarikoski, S., Sillanpää, M., Sofiev, M., Timonen, H., Saarnio, K., Teinilä, K., Karppinen, A., Kukkonen, J. \& Hillamo, R., Chemical composition of aerosols during a major biomass burning episode over northern Europe in spring 2006: experimental and modelling assessments. Atmospheric Environment, 41, pp. 3577-3589, 2007.

[3] van der Werf, G.R., Randerson, J.T., Collatz, G.J., Giglio, L., Kasibhatla, P.S., Arellano, A.F., Olsen, S.C. \& Kasischke, E.S., Continental-scale partitioning of fire emissions during the 1997 to 2001 El Niño/La Niña period, Science, 303, pp. 73-76, 2004.

[4] van der Werf, G.R., Randerson, J.T., Giglio, L., Collatz, G.J., Kasibhatla, P. S., Arellano, A.F. Jr., (2006) Interannual variability in global biomass burning emissions from 1997 to 2004. Atmospheric Chemistry and Physics, 6, pp. 3423-3441, 2006.

[5] Duncan B.N., Martin, R.V., Staudt, A.C., Yevich, R., Logan, J.A. Interannual and seasonal variability of biomass burning emissions constrained by satellite observations. Journal of Geophysical Research, 108(D2), pp. ACH1.1-ACH1.22, 2003.

[6] Giglio, L., Csiszar, I. \& Justice, C.O., Global distribution and seasonality of active fires as observed with the Terra and Aqua Moderate Resolution Imaging Spectrometer (MODIS) sensors. Journal of Geophysical Research, 111(G2), pp. G02016.1-G02016.12, 2006.

[7] Simon, M., Plummer, S., Fierens, F., Hoelzemann, J.J. \& O. Arino, Burnt area detection at global scale using ATSR-2: The GLOBSCAR products and their qualification, Journal of Geophysical Research, 109(D14), pp. D14S02.1-D14S02.16, 2004. 
[8] Ichoku, C. \& Kaufman, Y.J., A method to derive smoke emission rates from MODIS fire radiative energy measurements, IEEE Transactions on Geoscience and Remote Sensing, 43(11), pp. 2636-2649, 2005.

[9] Boschetti, L., Eva, H.D., Brivio, P.A. \& Gregoire, J.M., Lessons to be learned from the comparison of three satellite-derived biomass burning products. Geophysical Research Letters, 31(21), pp. L21501.1-L21501.4, 2004.

[10] Giglio, L., Descloitres, J., Justice, C.O. \& Kaufman, Y.J., An enhanced contextual fire detection algorithm for MODIS. Remote Sensing of Environment, 87, pp. 273-282, 2003.

[11] Dozier, J., A method for satellite identification of surface temperature fields of subpixel resolution. Remote Sensing of Environment, 11, pp. 221-229, 1981.

[12] Matson, M. \& Dozier, J., Identification of subresolution high temperature sources using a thermal IR sensor. Photogrammetric Engineering and Remote Sensing, 47, pp. 1311-1318, 1981.

[13] Sofiev M., Siljamo, P., Valkama, I., Ilvonen, M. \& Kukkonen, J., A dispersion modelling system SILAM and its evaluation against ETEX data. Atmospheric Environment, 40(4), pp. 674-685, 2006.

[14] Sofiev, M., Siljamo, P., Ranta, H., Linkosalo, T., Jaeger, S., Jaeger, C., Rassmussen, A., Severova, E., Oksanen, Karppinen, A., Kukkonen, J., From Russia to Iceland: an evaluation of a large-scale pollen and chemical air pollution episode during April and May, 2006. Aerobiological Monographs, 1, 2008, in press.

[15] http://silam.fmi.fi 